\title{
A period of 10 weeks of increased protein consumption does not alter faecal microbiota or volatile metabolites in healthy older men: a randomised controlled trial
}

\author{
S. M. Mitchell ${ }^{1,2}$, E. J. McKenzie ${ }^{3}$, C. J. Mitchell ${ }^{1,4}$, A. M. Milan ${ }^{1,5,6}$ (D) N. Zeng ${ }^{1}$, R. F. D’Souza ${ }^{1,7,8}$, \\ F. $\operatorname{Ramzan}^{1}$, P. Sharma ${ }^{1}$ (1) E. Rettedal ${ }^{5}$, S. O. Knowles $^{5}$ (1), N. C. Roy ${ }^{1,2,5,6}$, A. Sjödin ${ }^{9}$, K.-H. Wagner ${ }^{10}$, \\ J. M. O’Sullivan ${ }^{1}$ (ID and D. Cameron-Smith ${ }^{1,2,11_{*}}$ \\ ${ }^{1}$ Liggins Institute, University of Auckland, Auckland, New Zealand \\ ${ }^{2}$ Riddet Institute, Massey University, Palmerston North, New Zealand \\ ${ }^{3}$ Department of Physiology, University of Auckland, Auckland, New Zealand \\ ${ }^{4}$ School of Kinesiology, University of British Columbia, Vancouver, Canada \\ ${ }^{5}$ Food Nutrition \& Health Team, AgResearch, Palmerston North, New Zealand \\ ${ }^{6}$ The High-V alue Nutrition National Science Challenge, Auckland, New Zealand \\ ${ }^{7}$ Discipline of Nutrition, School of Medical Sciences, University of Auckland, Auckland, New Zealand \\ ${ }^{8}$ Maurice Wilkins Centre for Molecular Biodiscovery, University of Auckland, Auckland, New Zealand \\ ${ }^{9}$ Department of Nutrition, Exercise and Sports, Copenhagen University, Copenhagen, Denmark \\ ${ }^{10}$ Department of Nutritional Sciences and Research Platform Active Ageing, University of Vienna, Vienna, Austria \\ ${ }^{11}$ Singapore Institute for Clinical Sciences, Agency for Science, Technology, and Research, Singapore
}

(Received 8 May 2020 - Accepted 18 May 2020)

Journal of Nutritional Science (2020), vol. 9, e25, page 1 of 13

doi:10.1017/jns.2020.15

Abstract

Diet has a major influence on the composition and metabolic output of the gut microbiome. Higher-protein diets are often recommended for older consumers; however, the effect of high-protein diets on the gut microbiota and faecal volatile organic compounds (VOC) of elderly participants is unknown. The purpose of the study was to establish if the faecal microbiota composition and VOC in older men are different after a diet containing the recommended dietary intake (RDA) of protein compared with a diet containing twice the RDA (2RDA). Healthy males (74.2 (SD 3.6) years; $n 28)$ were randomised to consume the RDA of protein $(0.8 \mathrm{~g}$ protein $/ \mathrm{kg}$ body weight per $\mathrm{d})$ or $2 \mathrm{RDA}$, for 10 weeks. Dietary protein was provided via whole foods rather than supplementation or fortification. The diets were matched for dietary fibre from fruit and vegetables. Faecal samples were collected pre- and postintervention for microbiota profiling by $16 \mathrm{~S}$ ribosomal RNA amplicon sequencing and VOC analysis by head space/solid-phase microextraction/GCMS. After correcting for multiple comparisons, no significant differences in the abundance of faecal microbiota or VOC associated with protein fermentation were evident between the RDA and 2RDA diets. Therefore, in the present study, a twofold difference in dietary protein intake did not alter gut microbiota or VOC indicative of altered protein fermentation.

Key words: Microbiome: Recommended dietary intake: Volatile organic compounds: Fermentation: 16S amplicon sequencing

Abbreviations: 16S rRNA, 16S ribosomal RNA; 2RDA, diet containing twice the RDA of protein; AMDIS, Automated Mass Spectral Deconvolution and Identification System; BCFA, branched-chain fatty acid; HS/SPME/GCMS, head space/solid-phase microextraction/GC-MS; MaAsLin, Multivariate Association with Linear Model; RDA, diet containing the RDA of protein; VOC, volatile organic compound.

* Corresponding author: D. Cameron-Smith, email d.cameron-smith@auckland.ac.nz

(C) The Author(s), 2020. Published by Cambridge University Press on behalf of The Nutrition Society. This is an Open Access article, distributed under the terms of the Creative Commons Attribution licence (http://creativecommons.org/licenses/by/4.0/), which permits unrestricted re-use, distribution, and reproduction in any medium, provided the original work is properly cited. 
Life expectancy is increasing and, with it, a steady rise in the proportion of older adults worldwide ${ }^{(1)}$. Accordingly, it is crucial to understand optimal nutrient intakes, such that wider evidence-based dietary recommendations can be made for the elderly. The current RDA of protein for all adults aged over 19 years according to the $\mathrm{WHO}^{(2)}$ and the United States Department of Agriculture ${ }^{(3)}$ is $0.8 \mathrm{~g}$ protein $/ \mathrm{kg}$ body weight per $\mathrm{d}$. New evidence suggests that the protein requirements of the elderly should be reconsidered ${ }^{(4)}$, in part to compensate for age-related losses in muscle mass and function (sarcopenia) ${ }^{(5)}$. Ageing alters gastrointestinal tract physiology and function, potentially limiting the digestion of protein ${ }^{(6)}$. Regardless, greater protein intake leads to greater quantities of dietary protein entering the distal gut ${ }^{(7)}$, and this has been linked to the pathogenesis of various chronic disease ${ }^{(8-11)}$.

The gut microbiome is a complex community of microorganisms, essential for the maintenance of host health ${ }^{(12)}$. Microbial fermentation of nutrients in the lower gut produces a vast range of metabolites that have an impact on the colonic environment, the epithelium, and can be transported to other host tissues ${ }^{(13)}$. Both metabolite production and microbiota composition are highly contingent on nutrient availability ${ }^{(14,15)}$. Although the gut microbiome can also be resilient against short-term dietary change ${ }^{(16)}$, numerous studies have demonstrated some plasticity of the gut microbiome through dietary interventions $^{(17-19)}$.

Carbohydrates are the most studied dietary components relating to gut microbiota composition and metabolite production. Diets rich in non-digestible carbohydrates such as NSP and resistant starch increase the abundance of SCFA, particularly butyrate, and abundance of saccharolytic bacteria (for example, Bifidobacterium and Lactobacillus). SCFA are an important source of nutrients and protect against cancer and inflammation $^{(20)}$. By contrast, few studies have investigated the effect of high-protein diets on the gut microbiome. Of the current literature, increased dietary protein is only examined along with simultaneous energy deficits and/or coupled with an altered relative proportion of fibre intake, thereby introducing potential significant confounding. In those studies, products of protein fermentation such as faecal branched-chain fatty acids (BCFA), amines, phenols and indoles were increased ${ }^{(21)}$. When produced in high concentrations, metabolites derived from protein fermentation are implicated in DNA damage, inflammation, chronic kidney disease, CVD and cancer ${ }^{(21,22)}$. In addition, high-protein diets reduced SCFA-producing bacteria with a concomitant decline in $\operatorname{SCFA}^{(17,18,23)}$. It is likely that the reduction in carbohydrate rather than the increased protein is the culprit here. Indeed, studies have demonstrated the moderating effect of non-digestible carbohydrates on the proteolytic activity of gut microbiota, by increasing SCFA abundance and decreasing proteolytic metabolites such as phenol ${ }^{(24}$ 27). However, evidence for the effects of fibre-rich high-protein diets on gut microbiota and metabolite production is scarce.

Numerous studies have investigated the gut microbiome of elderly populations ${ }^{(28)}$. Profiles of their gut microbiota relative to younger counterparts are characterised by reduced diversity, reduction in beneficial species, and a shift in dominant species $^{(29)}$. However, given the heterogeneity of the elderly population due to lifestyle, living situation and co-morbidities including medication use, a typical microbiota composition is difficult to define ${ }^{(28)}$. Compared with younger adults, concentrations of faecal SCFA tend to be lower in elderly individuals, and studies in elders treated with antibiotics and centenarians have demonstrated a decline in saccharolytic gut bacteria such as Bifidobacterium and increased numbers of facultative proteolytic bacteria ${ }^{(30-32)}$. To date, no randomised controlled trials have investigated the impact of increased dietary protein intake on the composition and diversity of the gut microbiome and metabolite production, in the context of an otherwise healthy and balanced diet in the community-dwelling elderly.

In light of the mounting recommendations for increasing the RDA of protein for elderly ${ }^{(33)}$, and the potential for greater proteolytic gut microbial metabolism in this age group, consideration for the implications of increased protein intake on gut health is relevant. Therefore we investigated the impact of a controlled 10-week diet containing either the RDA $(0.8 \mathrm{~g} / \mathrm{kg}$ body weight per d) or 2RDA (twice the RDA) of protein in the context of a whole-food diet providing similar quantities per group of fibre, derived from fruits and vegetables, on the composition and diversity of the gut microbiota and production of gut bacteria-derived metabolites. We hypothesised that the 2RDA diet would lead to an increase in protein-fermenting gut bacteria and metabolites of protein fermentation.

\section{Methods}

\section{Study design}

The study was a 10-week randomised parallel-group design. Allocation (1:1 ratio) was conducted by using a locked spreadsheet that assigned participants to treatment groups. The study was not blinded as the investigators were involved in diet preparation, and due to the types of food provided the participants were aware of which group they were assigned. Ethical approval was obtained from the Southern Health and Disability Ethics Committee (New Zealand; 15/STH/236). The trial was conducted according to the Declaration of Helsinki. The study was prospectively registered with the Australian and New Zealand Clinical Trial Registry (www. anzctr.org.au) as ACTRN no. 12616000310460. Informed written consent was obtained from all participants before they were enrolled in the trial. This article reports on secondary outcomes of the OptiMuM (Optimal nutrition in the elderly: High protein diets for muscular, metabolic, and microbiome health) study. The primary outcome for OptiMuM was to evaluate the ability of a high-protein diet to attenuate loss of muscle function and size in healthy ageing males. The secondary outcomes reported in this paper included assessment of faecal microbiota composition and diversity, and faecal metabolites (volatile organic compounds; VOC).

\section{Participants}

A total of thirty-one participants were recruited and thirty were enrolled in the study (Table 1). Eligible participants were males aged 70 years and over, non-smokers, and with a BMI between 
Table 1. Participant characteristics pre-intervention (Mean values, standard deviations and ranges; numbers of participants)

\begin{tabular}{|c|c|c|c|c|c|c|c|c|}
\hline \multirow[b]{2}{*}{ Parameter } & \multicolumn{4}{|c|}{ RDA group } & \multicolumn{4}{|c|}{ 2RDA group } \\
\hline & Mean & SD & Range & $n$ & Mean & $\mathrm{SD}$ & Range & $n$ \\
\hline Number of participants* & & & & 15 & & & & 13 \\
\hline Age (years) & $74 \cdot 7$ & 3.9 & $70-81$ & & $73 \cdot 7$ & $3 \cdot 3$ & $70-79$ & \\
\hline Height $(\mathrm{cm})$ & $172 \cdot 8$ & 8.2 & $157-187$ & & $171 \cdot 7$ & $5 \cdot 5$ & $163-182$ & \\
\hline Weight (kg) & $85 \cdot 7$ & 20.5 & $49 \cdot 3-111 \cdot 8$ & & $83 \cdot 0$ & $8 \cdot 3$ & $70 \cdot 5-98 \cdot 1$ & \\
\hline $\operatorname{BMI}\left(\mathrm{kg} / \mathrm{m}^{2}\right)$ & $28 \cdot 4$ & $5 \cdot 1$ & $18 \cdot 9-35 \cdot 3$ & & $28 \cdot 2$ & $3 \cdot 3$ & $24 \cdot 1-33.9$ & \\
\hline \multicolumn{9}{|l|}{ Medication usage } \\
\hline Statin & & & & 4 & & & & 6 \\
\hline ACE inhibitor & & & & 4 & & & & 3 \\
\hline Aspirin & & & & 4 & & & & 2 \\
\hline Ca channel blocker & & & & 1 & & & & 2 \\
\hline PPI & & & & 0 & & & & 2 \\
\hline$\alpha$-Blocker & & & & 1 & & & & 2 \\
\hline$\beta$-Blocker & & & & 1 & & & & 2 \\
\hline Xanthine oxidase inhibitor & & & & 1 & & & & 1 \\
\hline
\end{tabular}

RDA, diet containing the RDA of protein; 2RDA, diet containing twice the RDA of protein; ACE, angiotensin converting enzyme; PPI, proton pump inhibitors.

* Only the participants who completed the study were included in the analysis $(n 28)$.

20 and $35 \mathrm{~kg} / \mathrm{m}^{2}$. Participants who enrolled were not taking probiotics for at least 1 month or antibiotics for at least 3 months preceding study commencement. Individuals were excluded from participation if they had a prior history of cancers, diabetes, thyroid disease or gastrointestinal disease. Those with restricted eating habits including vegetarians and those with food allergies or intolerances were also not included in the study. Participants were recruited from Auckland, New Zealand and data were collected at the Liggins Institute, University of Auckland, between March and October 2016. Random assignment of individual participants into each group was performed using sequences generated by www.random.org ${ }^{(34)}$.

\section{Study procedures}

A detailed description of the study procedures and dietary control has been published previously ${ }^{(35)}$. Briefly, participants were randomised to receive either the RDA $(0 \cdot 8 \mathrm{~g}$ protein $/ \mathrm{kg}$ body weight per $\mathrm{d}$ ) or $2 \mathrm{RDA}(1.6 \mathrm{~g}$ protein $/ \mathrm{kg}$ body weight per d) for 10 weeks. The quantity of protein in the 2RDA diet was chosen as it has previously been recommended as optimal for preserving muscle mass in older adults ${ }^{(35)}$. Both diets provided approximately $30 \%$ of total energy from fat, with the remainder made up from carbohydrate. Protein was provided from a combination of animal and plant sources including dairy products, eggs, poultry, fish, red meat, legumes, grains, nuts and seeds. Both diets contained a similar amount of plant protein whereas the $2 \mathrm{RDA}$ diet contained a larger proportion of animal-sourced protein. The two diets were allocated the New Zealand recommendations for daily fruit and vegetable intake (at least five serves per $\mathrm{d})^{(36)}$. The energy content of the diets was calculated to match estimated energy needs for weight maintenance based on the Harris-Benedict equation and adjusted for physical activity level ${ }^{(37)}$ assessed by wrist-worn accelerometers (Fitbit Charge, HR; Fitbit, Inc.). All meals and snacks were provided by the investigators for the duration of the study and delivered weekly to the participants' homes. During the intervention, participants attended the University of Auckland Nutrition and Mobility Clinic at the Liggins Institute at weeks 4, 6 and 8 for weight measurement and compliance check. Participants were asked to make no changes to their exercise routine throughout their participation in the trial.

\section{Dietary analysis}

Individual habitual dietary intake (based on 3-d food diaries) and diets consumed during the trial were analysed using Foodworks software (version 8; Xyris Software Pty Ltd). Compliance was monitored via fortnightly visits and adjusted according to individual preferences within macronutrient allowances to assist with compliance.

\section{Sample collection}

For the analysis of gut microbiota composition and VOC abundance, faecal samples were collected pre-intervention (pre) and after 10 weeks of intervention (post). Participants were provided with a stool collection kit for home collection. Each kit contained a collection vessel to capture the sample, and two collection containers: one containing $2 \mathrm{ml}$ RNA-stabilising solution (RNAlater; Ambion) for bacterial nucleic acid extraction, and another for VOC analyses. Samples were delivered on ice within $2 \mathrm{~h}$ of collection via courier to the laboratory at the Liggins Institute. DNA extraction was processed within $5 \mathrm{~h}$ of arrival at the laboratory. Faecal samples for the VOC analysis were immediately stored at $-80^{\circ} \mathrm{C}$ for later processing. Uniform sample collection, handling and storage procedures were conducted according to recommendations to minimise bias and differences in detection of microbiota and $\mathrm{VOC}^{(38-40)}$.

\section{Faecal DNA extraction}

DNA extraction, bacterial 16S ribosomal RNA (16S rRNA) gene amplification and sequencing of the $16 \mathrm{~S}$ rRNA gene 
libraries were performed at the Liggins Institute laboratory. DNA was extracted from faecal samples using the AllPrep DNA/RNA Mini Kit (Qiagen) according to the modified procedures reported by Giannoukos et $a l^{(41)}$. The purity of extracted DNA was determined with a NanoDrop ${ }^{\mathrm{TM}}$ ND-1000 spectrophotometer (NanoDrop Technologies). Extracted DNA was stored $\left(100 \mu \mathrm{l}\right.$ aliquots; $\left.-80^{\circ} \mathrm{C}\right)$.

\section{Microbiota composition analysis by 165 ribosomal RNA amplicon sequencing}

DNA concentration was quantified on the Qubit ${ }^{\circledR} 2.0$ fluorometer (Thermo Fisher Scientific) using the Qubit ${ }^{\circledR}$ dsDNA High Sensitivity Assay Kit (ThermoFisher Scientific). The Ion $16^{\mathrm{TM}}$ Metagenomics Kit (Thermo Fisher Scientific) was used to amplify the $16 \mathrm{~S}$ rRNA gene. The kit contained two different sets of primers targeted to seven hypervariable regions of 16S rRNA: primer set 1 amplified three regions (V2, V4 and V8) and primer set 2 amplified four regions (V3, V6-V7 and V9). Amplicons were fragmented, nick repaired, adaptor ligated, and barcoded for library construction using the Ion Plus Fragment Library Kit (Thermo Fisher Scientific). Libraries were purified using Agencourt AMPure XP magnetic beads (Beckman Coulter). Adaptor-ligated libraries were prepared using the Ion Plus Fragment Library and Ion Xpress $^{\mathrm{TM}}$ barcode adaptors 1-16 (Thermo Fisher Scientific). Quantification was performed using the Agilent 2100 Bioanalyser with the DNA High Sensitivity Kit (Agilent Technologies). Equimolar concentrations from eight sample libraries $(26 \mathrm{pmol} / \mu \mathrm{l})$ were pooled for each sequencing run. Sequencing was performed on the Ion Torrent Personal Genome Machine (PGM) using the Ion PGM Hi-Q View Sequencing $400 \mathrm{Kit}$ and the Ion 318v2 chip (Thermo Fisher Scientific) at the Liggins Institute laboratory.

\section{Bioinformatic processing of 165 ribosomal RNA sequence reads}

16S amplicon sequences were classified according to the barcode and analysed using the Metagenomics 16S w1.1 workflow in the Ion Reporter software on the Thermo Fisher cloud (version 5.2; Thermo Fisher Scientific) with default parameters ${ }^{(42)}$. After sequencing, the binary alignment map (BAM) files are analysed by Ion Reporter software. Ion Reporter software uses Java scripts to filter the reads by primer and length, before measuring the abundance of each read. Following this, a two-step Basic Local Alignment Search Tool (BLAST) alignment of sequencing reads is performed against both the MicroSEQ (version 2013.1; Thermo Fisher Scientific) and Greengenes (version 13.5) databases. The completed analysis reported the results by consensus for three taxonomic levels (i.e. species, genus and family).

\section{Volatile organic compound analysis}

To determine VOC abundance, triplicates of approximately 200 (range 163-282) $\mathrm{mg}$ of frozen faecal material were subsampled from faecal samples that were not exposed to
RNAlater, and weighed into tared $20 \mathrm{ml}$ head space vials (Sigma Aldrich). Untargeted extraction of VOC was performed using head space/solid-phase microextraction/ GC-MS (HS/SPME/GCMS). Vials were incubated $\left(37^{\circ} \mathrm{C}\right.$; $25 \mathrm{~min})$, and volatiles were extracted $\left(37^{\circ} \mathrm{C} ; 15 \mathrm{~min}\right)$. The SPME fibres used were divinylbenzene-carboxen-polydimethysiloxane (DVB/CAR/PDMS) 50/30 $\mu \mathrm{m}$ (Supelco), selected for their ability to sample a wide range of VOC. The SPME fibres were pre-conditioned in accordance with the manufacturer's instructions. GCMS analysis was performed using an Agilent GC 7890A with a 5975C inert massselective detector (MSD) (Agilent Technologies). The carrier gas was instrument-grade He (99.99\%; BOC). The fibre was desorbed in the GC injector in splitless mode, using a butyl rubber septum and a low-volume SPME-specific glass liner $\left(0.75 \mathrm{~mm}\right.$ internal diameter (ID)) at $250^{\circ} \mathrm{C}$ for $1 \mathrm{~min}$. A general-purpose column was chosen for compound separation: an Rtx-5Sil MS $30 \mathrm{~m}, 0.25 \mathrm{~mm}$ ID, with a $0.25 \mu \mathrm{m}$ stationary phase $(95 \%$ dimethylpolysiloxane, $5 \%$ diphenyl; Shimadzu). Column flow was set $(1 \mathrm{ml} / \mathrm{min})$, with a column head pressure $(7.2 \mathrm{psi}$ (pound per square inch)), to provide an average linear velocity of $36 \mathrm{~cm} / \mathrm{s}$. The SPME fibre remained in the injector for $5 \mathrm{~min}$ to condition for the next run. Purge flow $(50 \mathrm{ml} / \mathrm{min})$ commenced $1 \mathrm{~min}$ after injection. The GC oven was initially set at $35^{\circ} \mathrm{C}$ for $5 \mathrm{~min}$, increasing to $100^{\circ} \mathrm{C}$ at $5^{\circ} \mathrm{C} / \mathrm{min}$, further to $200^{\circ} \mathrm{C}$ at $15^{\circ} \mathrm{C} / \mathrm{min}$, and finally to $300^{\circ} \mathrm{C}$ at $30^{\circ} \mathrm{C} / \mathrm{min}$, before being held for $3 \mathrm{~min}$, with a total run time of $31 \mathrm{~min}$. The detector source was maintained at $230^{\circ} \mathrm{C}$ and the quadrupole at $150^{\circ} \mathrm{C}$. The detector was run in positive-ion, electron-impact ionisation mode, at $70 \mathrm{eV}$. Data were acquired at 1789 atomic mass units $(\mathrm{amu}) / \mathrm{s}$ in scan mode, with a mass range of 24 to $300 \mathrm{amu}$, and zero threshold.

\section{Volatile organic compound data processing}

Deconvolution and identification of compounds were performed using the Automated Mass Spectral Deconvolution and Identification System (AMDIS, version 2.71) ${ }^{(43)}$. The AMDIS limitation on mass spectral library size was circumvented by developing a smaller subset library from the National Institute of Standards and Technology (NIST) main mass spectral library ${ }^{(44)}$. The subset library was constructed using Agilent MSD Productivity ChemStation (version F.01.01.2317) setting integration parameters to be sensitive to low-abundance compounds, and search-match parameters to be expansive. The top five identities for each peak, for all peaks, and for all samples were combined to construct a subset library of 17901 mass spectra, which were then used with AMDIS. The settings for AMDIS were optimised to maximise annotation of all features, including unknowns, reducing the false-negative rate to $<5 \%$. Mass spectral matching was used to assign identities. Matches $<60 \%$ are considered unknown and were excluded from analysis.

Matches between 80 and $100 \%$ match to a reference standard can be considered putatively identified, those with a 60-79\% mass spectral match can be considered tentatively identified, and those with $<60 \%$ mass spectral match can be 
considered unknown ${ }^{(45)}$. Data were filtered to exclude compounds that were identified at a low frequency $(<9$ identifications/156 samples) in the dataset. For peak integration an R-script based on XCMS (MassOmics, version 2.5) ${ }^{(46)}$ was used, with the retention time bins defined by AMDIS. The data produced represent a set of probable identifications for each feature, which were then filtered, based on frequency, retention time reproducibility, and library match factor to assign the most probable identification. Co-eluting peaks were resolved and data were checked against negative controls (empty vials) to identify and remove background contaminants.

\section{Statistical analysis}

The sample size (fifteen participants per group) was calculated based on the power required for the primary outcome for the original study, which was to detect a between-group difference of $800 \mathrm{~g}$ whole-body lean mass change in skeletal muscle mass and strength ${ }^{(35)}$. Previous studies investigating the effect of high-protein diets on the gut microbiome demonstrated significant changes in gut microbiota taxa and faecal metabolites in similar samples sizes $\left(n 14^{(47)}\right.$, and $\left.n 17^{(17)}\right)$.

Changes in dietary intake were assessed by two-way repeated-measures ANOVA with time (pre- compared with post-intervention) as a repeated factor and diet (RDA compared with 2RDA) as a between-subject factor. ANOVA was performed using SPSS version 25.0 (SPSS Inc.).

For microbiota analysis, comparisons of $\alpha$-diversity were made by Kruskal-Wallis tests using the Shannon and Simpson indices to determine within-sample richness and evenness. To determine whether the level of variability within groups was not greater than between groups, homogeneity of group dispersions (PERMDISP) was performed. $\beta$-Diversity was assessed by permutational multivariate ANOVA (PERMANOVA). Principal coordinate analysis (PCoA) was applied to illustrate the variation present between groups. Statistics and data visualisation for microbiota analysis were carried out with the use of MicrobiomeAnalyst ${ }^{(48)}$.

For the VOC analysis, triplicate samples were averaged by the median and raw data were normalised by the auto scaling method (mean-centred and divided by the standard deviation of each variable). Estimation of main or interaction effects was calculated using ANOVA simultaneous component analysis (ASCA). Univariate analyses of postintervention results were made by the Wilcoxon-MannWhitney test. Principal components analysis (PCA) was applied to illustrate variation between groups postintervention. Statistics for VOC analysis were performed using MetaboAnalyst v4.0 $0^{(49)}$. Multivariate Association with Linear Models (MaAsLin) was used to identify significant associations between microbiota taxa and VOC abundance $^{(50)}$. MaAsLin is a type of multivariate statistical analysis to find associations between clinical metadata and microbial composition or functional data. Where appropriate, $P$ values were corrected for multiple testing using false discovery rate according to the Benjamini-Hochberg correction. Significance was set at $P \leq 0 \cdot 05$. Mean values and standard deviations are shown in the tables and text.

\section{Results}

A total of thirty-one participants were recruited to the study (RDA, $n$ 15, 2RDA, $n$ 16; Fig. 1). One subject dropped out before commencement of the study (2RDA, $n$ 1) and one was excluded due to non-compliance (2RDA, $n 1$ ). One participant was excluded from the final analysis due to antibiotic use (2RDA, $n 1)$. The remaining twenty-eight participants were included in this analysis (RDA, $n 15 ; 2 \mathrm{RDA}, n 13)$. Participant characteristics are reported in Table 1.

\section{Dietary intake}

A detailed account of dietary intake is shown in Table 2 . Overall, participants were highly compliant with both diets (compliance for protein intake was $98.9 \%$ in the RDA group and $97.5 \%$ in the $2 \mathrm{RDA}$ group). Compliance was documented in fortnightly food records and according to urinary $\mathrm{N}$ excretion assessed pre- and post-intervention (RDA: from $1.3($ sD 0.2$)$ to 0.9 (sD 0.2$) \mathrm{g} / \mathrm{kg}$ body weight per d, $P=0 \cdot 001$; 2RDA: from 1.3 (sD $0 \cdot 2$ ) to 1.5 (SD $0 \cdot 1$ ) $\mathrm{g} / \mathrm{kg}$ body weight per $\mathrm{d}, P=0 \cdot 001)$. Average protein intake was altered by the intervention (time $\times$ diet interaction $P<$ $0 \cdot 001$ ); it reduced in the RDA group (from 104.8 (SD 30) to $80 \cdot 1$ (sD 23) $\mathrm{g} / \mathrm{d}, P=0.004$ ) and increased in the $2 \mathrm{RDA}$ group (from $95 \cdot 6$ (sD 20) to $136 \cdot 2$ (sD 18$) \mathrm{g} / \mathrm{d} ; P<0 \cdot 001$ ). Dietary fibre increased (time effect, $P<0.001$ ) for RDA (from 34 (sD 9.9) to $47(\mathrm{sD} 8.4) \mathrm{g} / \mathrm{d} ; P<0.001$ ), and for 2RDA (from 28.9 (sD 8.1) to $50.3($ sD 5.3$) \mathrm{g} / \mathrm{d} ; P<0.001$ ) but was not different between the diets $(P=0 \cdot 410)$.

\section{Microbial taxa composition}

An average of 398372 filtered 16S rRNA sequence reads were obtained per sample. Library size was rarefied to a minimum read depth of 189549 . When corrected for multiple testing, there were no differences in relative abundance observed at the phylum, family, genus or species level between groups (genus level post-intervention illustrated in Fig. 2). The most abundant genera in both groups pre- and post-intervention were Bacteroides, Faecalibacterium, Roseburia, Eubacterium, Clostridium and Ruminococcus (Fig. 3).

\section{Microbial diversity}

$\alpha$-Diversity was assessed using the Simpson and Shannon indices (Fig. 4). There was no change over time in $\alpha$-diversity for the RDA (Shannon, $P=0.632$; Simpson, $P=0.935$ ) or the 2RDA groups (Shannon, $P=0.250$; Simpson, $P=0.945$ ). There was also no significant difference in $\alpha$-diversity between groups pre-intervention (Shannon, $P=0 \cdot 650$; Simpson, $P=$ 0.339 ) or post-intervention (Shannon, $P=0.548$; Simpson, $P=0.525)$. Between groups, there was no difference in $\beta$-diversity $(P=0 \cdot 154$; Fig. 5$)$, and the graph demonstrates that individuals (pre- and post-samples) clustered more 


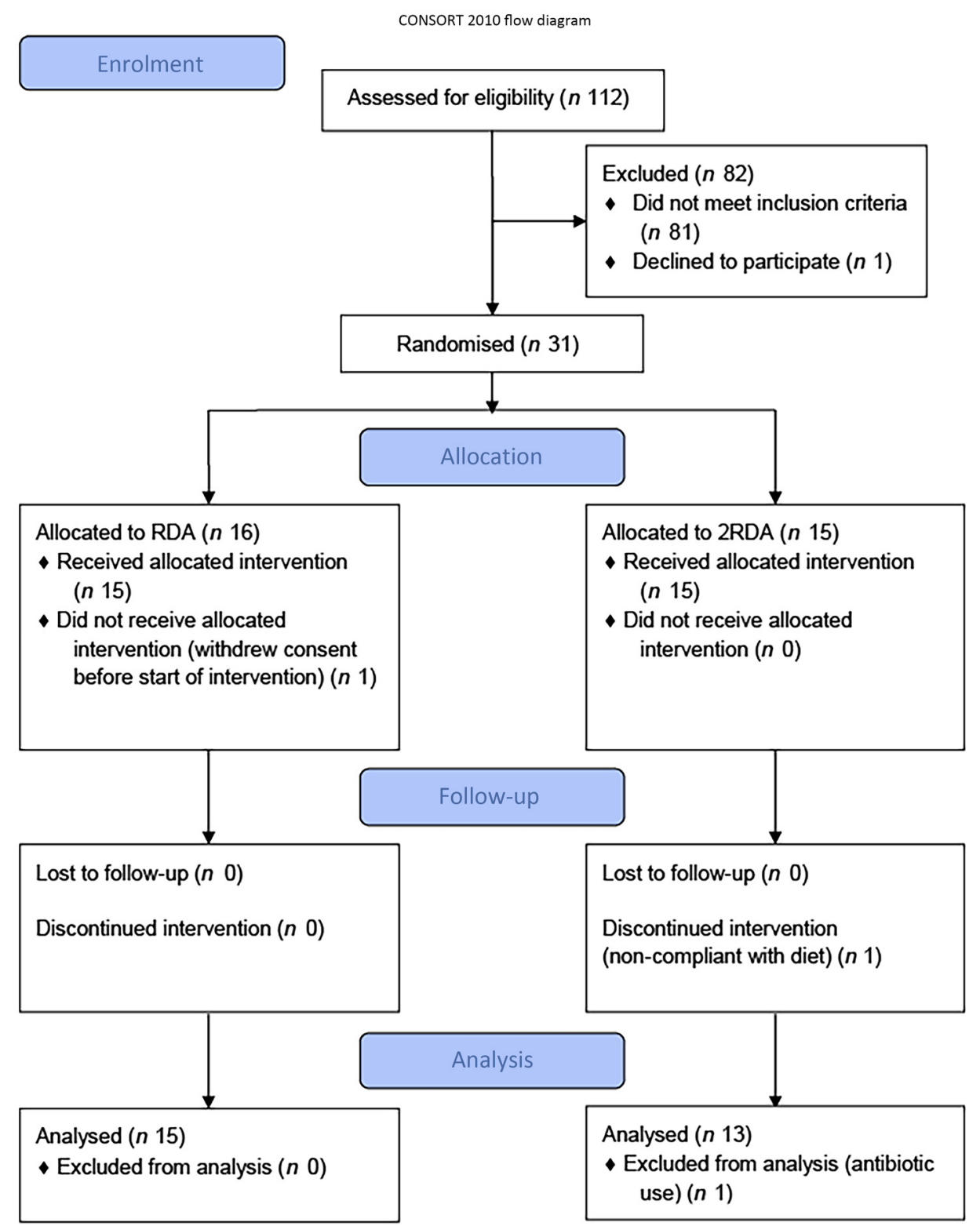

Fig. 1. CONSORT (Consolidated Standards of Reporting Trials) diagram. RDA, diet containing the RDA of protein; 2RDA, diet containing twice the RDA of protein.

strongly together than the diet groups. PERMDISP revealed no variability within groups $(P=0 \cdot 284)$.

\section{Faecal volatile organic compound abundance}

Untargeted faecal metabolite analysis identified 261 VOC. These were collectively derived from a combination of ingested compounds (for example, from food or drink, inhaled, absorbed) or endogenous compounds (for example, from the microbial fermentation process). A representative list of VOC accompanied by a univariate analysis of post-intervention results is shown in Supplementary Table S1. After adjustment for multiple testing, there were no significant differences in any of the compounds related to bacterial fermentation of dietary components between groups post-intervention. Clustering of VOC for each group postintervention was plotted by principal components analysis (PCA) (Fig. 6) which showed no differential clustering between groups.
According to the ANOVA simultaneous component analysis (ASCA), permutation test statistics showed that there were no significant effect for time $(P=0.497)$, diet $(P=$ 0.440 ) or interaction (time $\times$ diet) $P=0.756$ ). There were six compounds of microbial metabolism well modelled by the main effect of time (Table 3 and Fig. 7). Indole increased in the RDA group from pre- to post-, and relative to the 2RDA group. In both groups, 3-methylbutanal decreased, while the fatty acid esters butyrate, 2-methyl-, hexyl ester; butyrate, 2-methyl-, propyl ester; and butyrate, 2-methyl-, butyl ester all increased in both groups.

\section{Correlations}

MaAsLin analysis between $16 \mathrm{~S}$ and VOC data revealed no significant correlations between microbial taxa (at family, genus or species level) and VOC abundance. 
Table 2. Estimated composition of baseline (pre) and experimental diets (post) for the RDA and 2RDA groups (Mean values and standard deviations)

\begin{tabular}{|c|c|c|c|c|c|c|c|c|c|c|c|}
\hline \multirow[b]{3}{*}{ Nutrient intake } & \multicolumn{4}{|c|}{$\mathrm{RDA}$} & \multicolumn{4}{|c|}{ 2RDA } & \multicolumn{3}{|c|}{ Effect $(P) \S$} \\
\hline & \multicolumn{2}{|c|}{ Pre } & \multicolumn{2}{|c|}{ Post } & \multicolumn{2}{|c|}{ Pre } & \multicolumn{2}{|c|}{ Post } & \multirow[b]{2}{*}{ Time } & \multirow[b]{2}{*}{ Diet } & \multirow[b]{2}{*}{ Time $\times$ diet } \\
\hline & Mean & SD & Mean & SD & Mean & SD & Mean & SD & & & \\
\hline Energy intake & & & & & & & & & 0.705 & 0.06 & $0.003^{*}$ \\
\hline $\mathrm{kJ} / \mathrm{d}$ & 13104 & 4418 & $11276 \ddagger$ & 2502 & $9305 \dagger$ & 2707 & $11627 \ddagger$ & 715 & & & \\
\hline $\mathrm{kcal} / \mathrm{d}$ & 3132 & 1056 & $2695 \ddagger$ & 598 & $2224 \dagger$ & 647 & $2779 \ddagger$ & 171 & & & \\
\hline \multicolumn{12}{|l|}{ Protein intake } \\
\hline Total (g/d) & 101 & 30 & $74 \ddagger$ & 15 & 88 & 25 & $136 \dagger \ddagger$ & 10 & $0.041^{*}$ & $0.001^{*}$ & $<0.001^{*}$ \\
\hline Relative (g/kg per d) & $1 \cdot 2$ & 0.4 & $0.9 \ddagger$ & 0.1 & $1 \cdot 1$ & 0.3 & $1 \cdot 7 \dagger \ddagger$ & 0.1 & 0.056 & $<0.001^{*}$ & $<0.001^{*}$ \\
\hline Animal sourced $(\mathrm{g} / \mathrm{d})$ & 58 & 20 & $35 \ddagger$ & 11 & 53 & 23 & $97 \dagger \ddagger$ & 6 & 0.016 & $<0.001^{*}$ & $<0.001^{*}$ \\
\hline Plant sourced $(\mathrm{g} / \mathrm{d})$ & 43 & 16 & 48 & 9 & 35 & 9 & 47 & 4 & $0.002^{*}$ & 0.177 & 0.185 \\
\hline Estimated by $\mathrm{N}$ balance $(\mathrm{g} / \mathrm{kg}$ per $\mathrm{d})$ & $1 \cdot 3$ & 0.2 & $0.9 \ddagger$ & 0.2 & $1 \cdot 3$ & 0.2 & $1.5 † \ddagger$ & 0.1 & 0.098 & $<0.001^{*}$ & $<0.001^{\star}$ \\
\hline Energy from protein (\%) & $13 \cdot 7$ & 4.4 & $11 \cdot 2 \ddagger$ & $1 \cdot 5$ & $16 \cdot 5$ & $4 \cdot 4$ & $19 \cdot 7 \dagger \ddagger$ & 1.6 & 0.644 & $<0.001^{*}$ & $0.001^{*}$ \\
\hline \multicolumn{12}{|l|}{ Carbohydrate intake } \\
\hline Total (g/d) & 288 & 107 & 368 & 94 & 264 & 102 & 340 & 30 & $0.001^{*}$ & 0.309 & 0.946 \\
\hline Relative $(\mathrm{g} / \mathrm{kg} / \mathrm{d})$ & 3.5 & $1 \cdot 2$ & 4.4 & 1.0 & $3 \cdot 3$ & 1.5 & $4 \cdot 2$ & 0.6 & $0.001^{*}$ & 0.493 & 0.915 \\
\hline Energy from carbohydrate (\%) & $37 \cdot 7$ & 9.8 & $54 \cdot 4 \ddagger$ & $2 \cdot 5$ & $47 \cdot 2 \dagger$ & 10.5 & $49.0 \dagger$ & $2 \cdot 2$ & $<0.001^{\star}$ & 0.217 & $0.001^{\star}$ \\
\hline Fibre intake (g/d) & 34 & 14 & $57 \ddagger$ & 9 & 33 & 15 & $50 \ddagger$ & 5 & $<0.001^{*}$ & 0.236 & 0.306 \\
\hline Fruit and vegetables (serves/d) & $5 \cdot 4$ & 3.0 & $8 \cdot 6 \ddagger$ & $2 \cdot 1$ & 4.5 & $2 \cdot 1$ & $8.5 \ddagger$ & $1 \cdot 6$ & $<0.001$ & 0.41 & 0.535 \\
\hline \multicolumn{12}{|l|}{ Fat intake } \\
\hline Total $(\mathrm{g} / \mathrm{d})$ & 161 & 86 & $91 \ddagger$ & 19 & $75 \dagger$ & 31 & 84 & 6 & $0.015^{\star}$ & $0.002^{*}$ & $0.002^{*}$ \\
\hline Energy from fat (\%) & $44 \cdot 6$ & $11 \cdot 0$ & $30 \cdot 4 \ddagger$ & $1 \cdot 9$ & $30.4 \dagger$ & $7 \cdot 3$ & $27 \cdot 2 \dagger$ & 1.3 & $<0.001^{*}$ & $<0.001^{*}$ & $0.006^{*}$ \\
\hline Saturated fat $(g / d)$ & 57 & 27 & $33 \ddagger$ & 8 & $29 \dagger$ & 13 & $28 \dagger$ & 4 & $0.005^{*}$ & $<0.001^{*}$ & $0.011^{*}$ \\
\hline Cholesterol (mg) & 387 & 142 & 299 & 83 & 351 & 113 & 527 & 73 & 0.106 & 0.003 & $<0.001$ \\
\hline Alcohol (g/d) & $8 \cdot 8$ & $15 \cdot 7$ & - & & 9.6 & $8 \cdot 6$ & - & & - & 0.236 & - \\
\hline
\end{tabular}

RDA, diet containing the RDA of protein; 2RDA, diet containing twice the RDA of protein

* Significant main effect or interaction $(P<0.05)$.

† Different between diets at indicated time point. $P$ values were controlled using the Sidak post hoc procedure.

$\ddagger$ Different from pre-intervention within the same group $(P<0.05)$.

$\S$ Main effects and interactions were calculated by two-way repeated-measures ANOVA. Modified from Mitchell et al. ${ }^{(35)}$, used with permission.

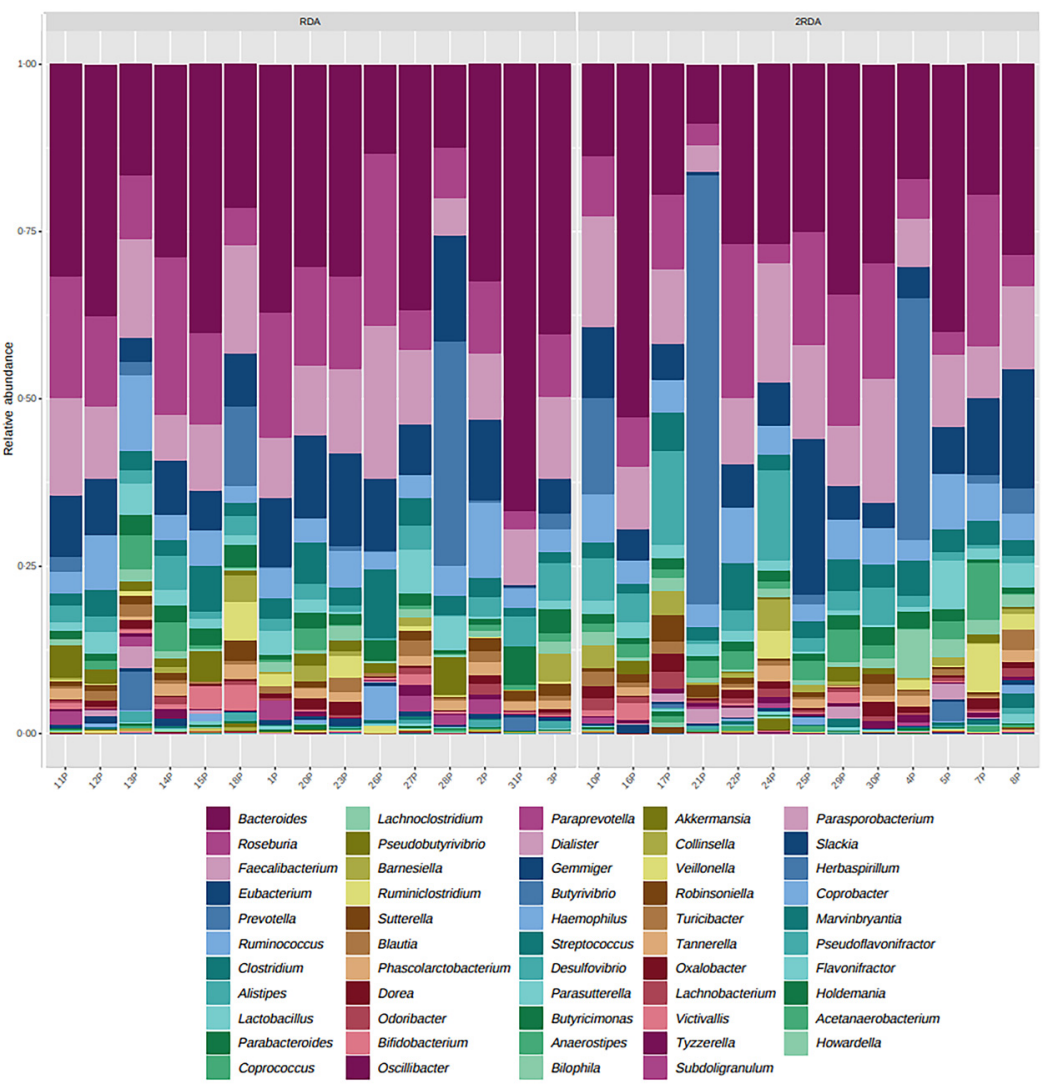

Fig. 2. Microbiota composition. Relative abundance at the genus level post-intervention in the RDA and 2RDA groups. RDA, diet containing the RDA of protein 2RDA, diet containing twice the RDA of protein. 
(a)

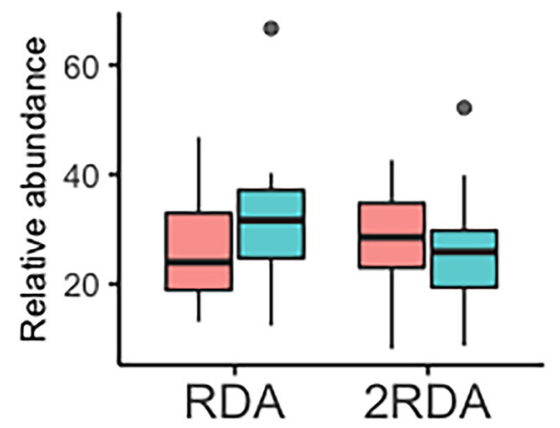

(d)

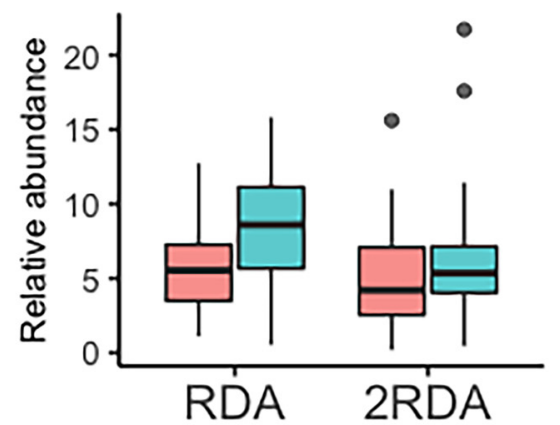

(b) Faecalibacterium

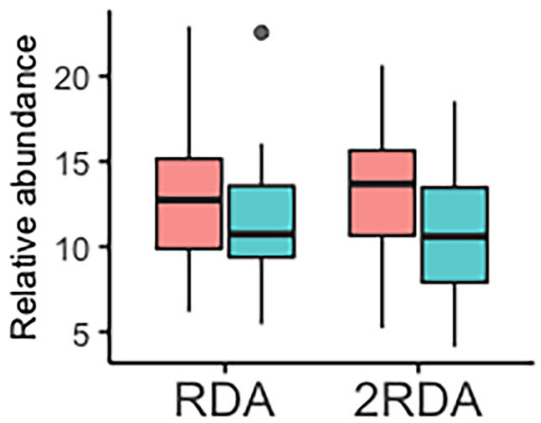

(e)

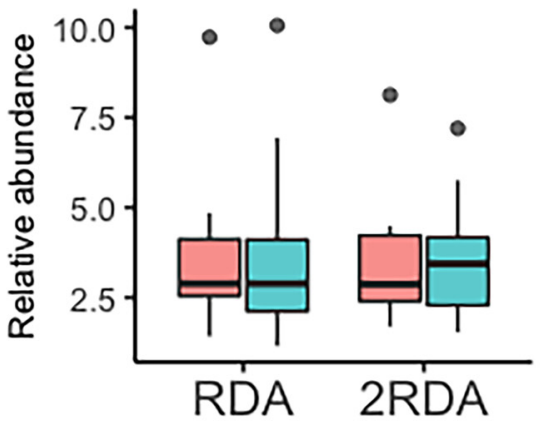

(c)

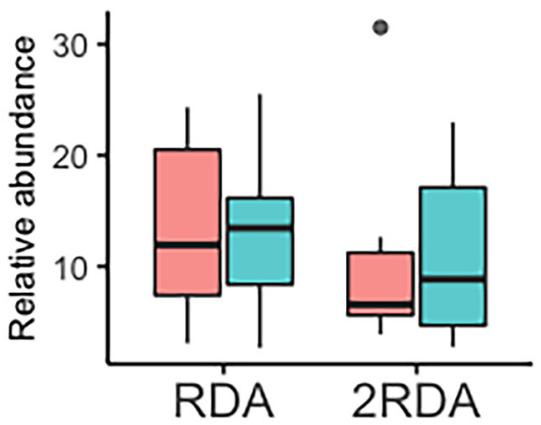

(f)

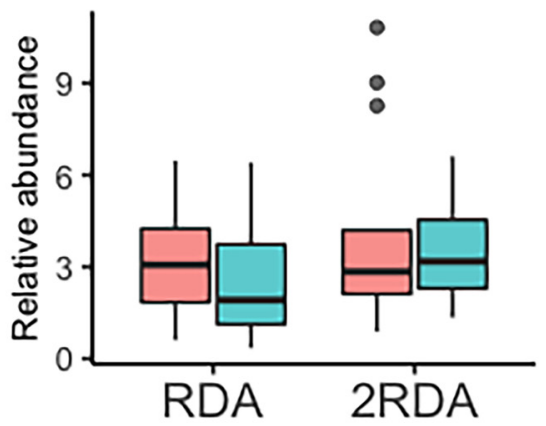

\section{Time 追 Pre 追 Post}

Fig. 3. Genera boxplots: the most abundant genera in the RDA and 2RDA groups. RDA, diet containing the RDA of protein; 2RDA, diet containing twice the RDA of protein. For the box plots: middle line is the median, boxes represent 25th and 75th percentiles, whiskers are within 1.5 interquartile ranges of the lower and upper percentiles, and dots represent outliers.

\section{Discussion}

The diet is an important modulator of the gut microbiome and its metabolites ${ }^{(51)}$, with potential important implications for health in an ageing population ${ }^{(30)}$. Here, we collected and analysed faecal samples for microbial DNA and VOC of bacterial fermentation origin, with the aim of characterising the impact
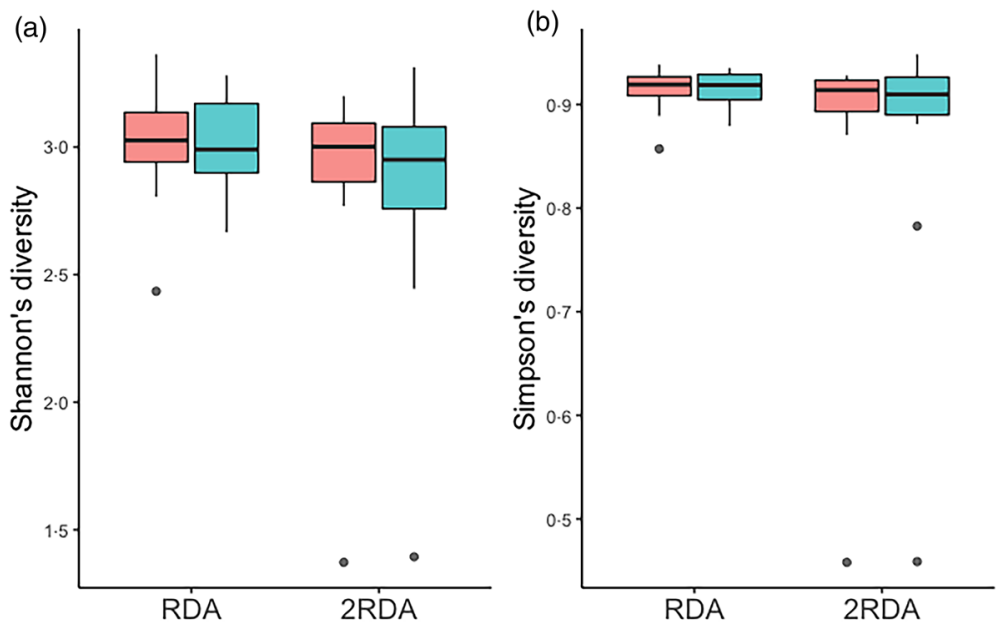

Time 追 Pre 追 Post

Fig. 4. $\alpha$-Diversity. (a) Shannon's diversity; (b) Simpson's diversity. RDA, diet containing the RDA of protein; 2RDA, diet containing twice the RDA of protein. For the box plots: middle line is the median, boxes represent 25th and 75th percentiles, whiskers are within 1.5 interquartile ranges of the lower and upper percentiles, and dots represent outliers. 


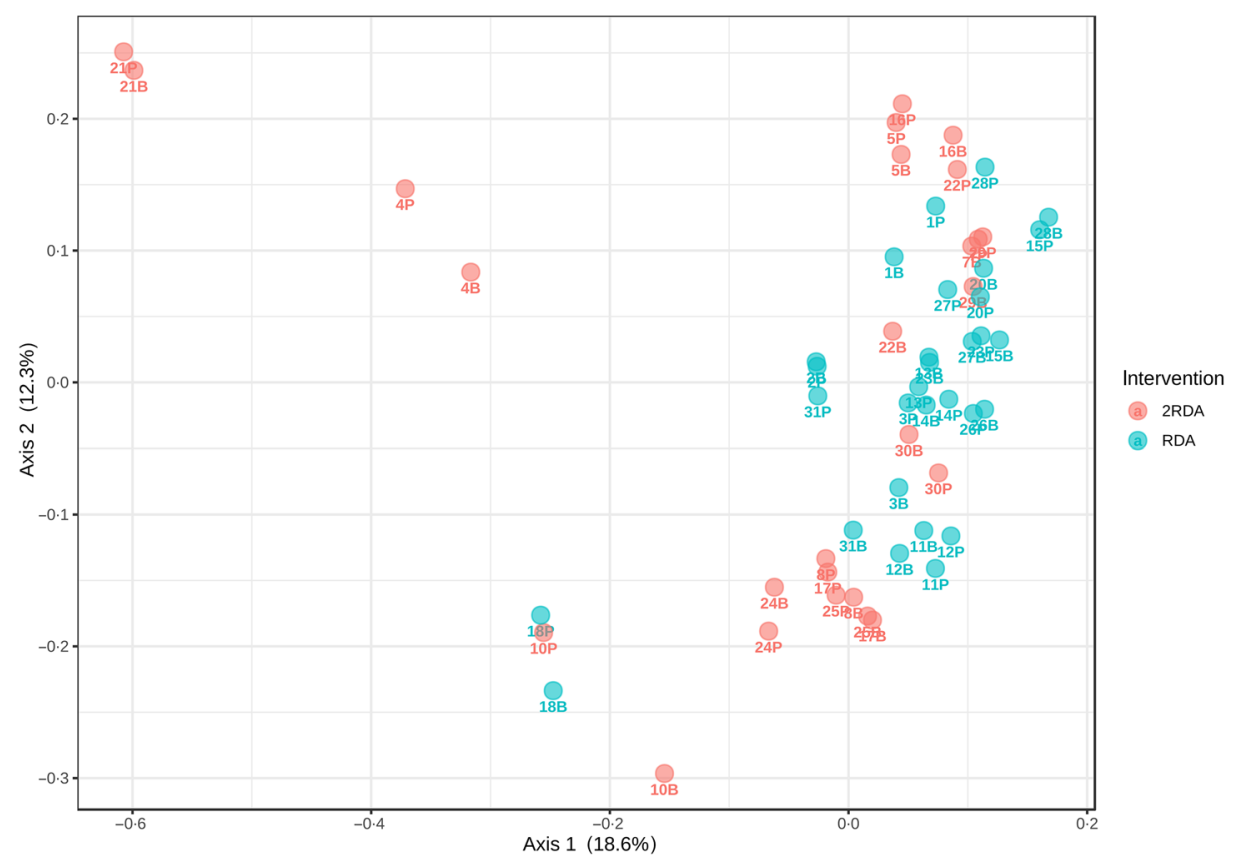

Fig. 5. $\beta$-Diversity. RDA, diet containing the RDA of protein; $2 R D A$, diet containing twice the RDA of protein.

of a high-protein diet on healthy older males. The present data indicate that contrary to the hypothesis, a diet containing twice the current RDA of protein, in conjunction with high fibre intake, did not modify the gut microbiota composition nor microbiota-derived VOC production after 10 weeks.
Overall, there was no statistically significant difference in the composition and diversity of the faecal microbiota between groups post-intervention. Ours was the first study to test the effects of a high-protein diet using whole foods as a protein source rather than supplements, while simultaneously

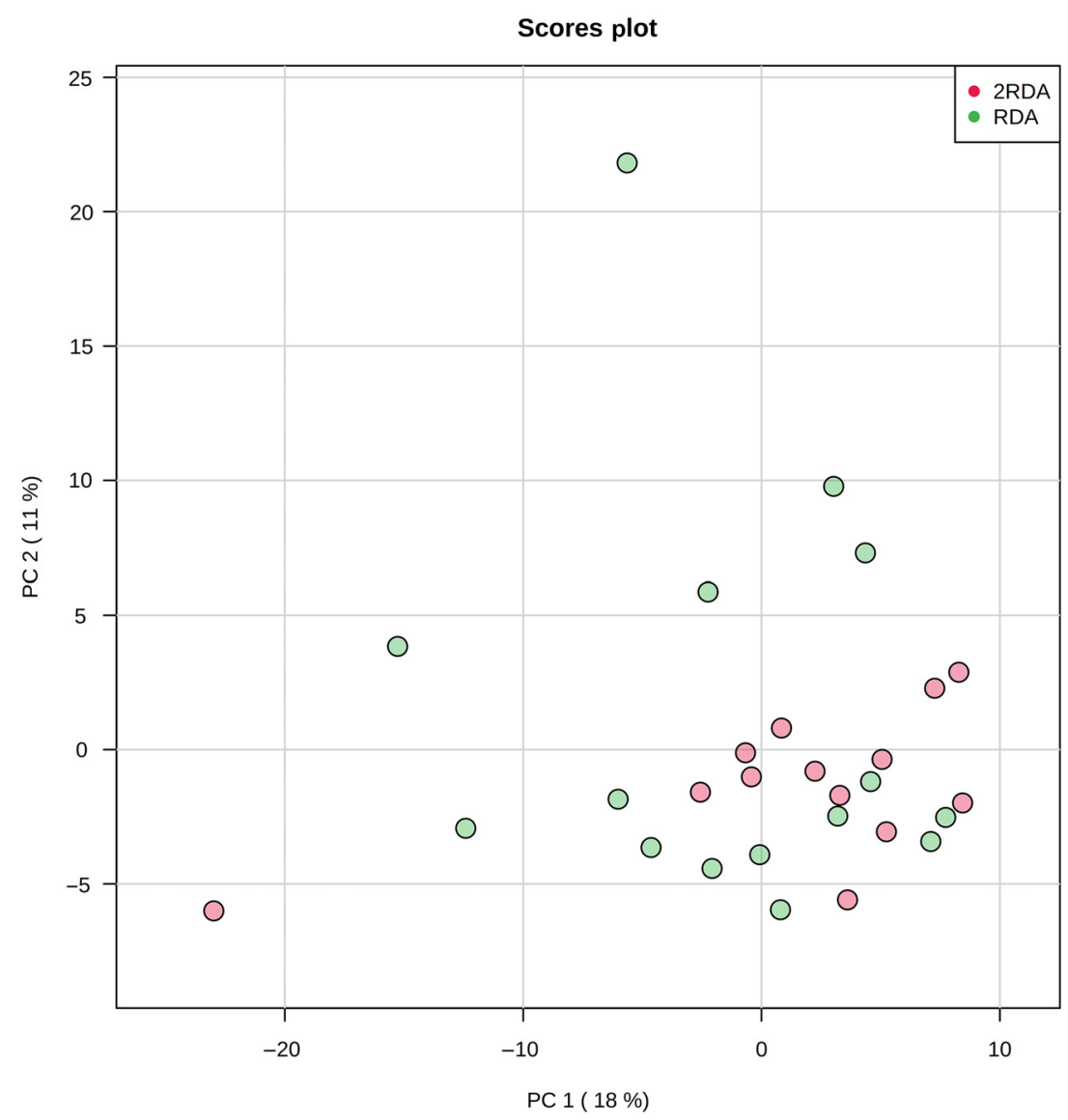

Fig. 6. Principal component $(P C)$ analysis of volatile organic compounds. RDA, diet containing the RDA of protein; $2 R D A$, diet containing twice the RDA of protein. 
Table 3. Important features identified by ANOVA simultaneous component analysis (ASCA) related to microbial fermentation*

\begin{tabular}{lcl}
\hline VOC & Leverage & \multicolumn{1}{c}{ SPE } \\
\hline Indole & 0.018 & 0 \\
3-Methylbutanal & 0.018 & $8.63 \times 10^{-32}$ \\
Butyrate, 2-methyl-, hexyl ester & 0.014 & $8.63 \times 10^{-32}$ \\
2-Butanol & 0.013 & $8.63 \times 10^{-32}$ \\
Butyrate, 2-methyl-, propyl ester & 0.012 & 0 \\
Butyrate, 2-methyl-, butyl ester & 0.011 & $1.08 \times 10^{-31}$
\end{tabular}

VOC, volatile organic compound; SPE, squared prediction error.

* Table includes the compounds well modelled by the main effect of time.

increasing fibre intake. The present result is in accord with two short-term dietary studies which investigated a high-protein diet with no change in fibre intake ${ }^{(52,53)}$. Beaumont $e t$ al. ${ }^{(52)}$ detected no difference in gut microbiota composition of participants consuming for 3 weeks a daily casein or soya supplement (total protein 34 and $31 \%$ of energy and total fibre intake 14.4 and $17.9 \mathrm{~g} / \mathrm{d}$, respectively), compared with a control group (total protein $14 \%$ of energy and total fibre $17 \mathrm{~g} / \mathrm{d}$ ) in a randomised parallel design ${ }^{(52)}$. Similarly, Windey et al. ${ }^{(53)}$ observed no effect between a control diet (total protein 15 $\%$ of energy intake and total fibre $16 \cdot 3 \mathrm{~g} / \mathrm{d}$ ) and a high-protein diet (total protein $27 \%$ of energy intake and total fibre $15.4 \mathrm{~g} /$ d) during 2 weeks in a randomised cross-over design ${ }^{(53)}$. In contrast, where protein intake has increased, concurrent with a reduction in dietary fibre, significant increases in
Bacteroides $^{(54)}$, and reductions in butyrate-producing bacteria including Roseburia, Eubacteria and Bifidobacterium, have been reported ${ }^{(17,18,23)}$. It is a reasonable interpretation that these observed differences were chiefly driven by alterations in the total malabsorbed carbohydrate, including dietary fibre, rather than the protein intake per se. These data support dietary fibre as a preferred fermentative substrate for microbiota ${ }^{(55)}$, even in the presence of substantial alterations in total protein intake and therefore potential increased protein malabsorption.

The VOC detected by HS/SPME/GCMS were not different in the 2RDA group relative to the RDA group. Protein fermentation by gut microbiota can result in a variety of compounds depending on the amino acids available. In the $\mathrm{RDA}$ group we observed a decrease in indole abundance over time, with no change in the $2 \mathrm{RDA}$ group. Indole is produced by a variety of microbiota species particularly from the Bacteroides gener ${ }^{(56)}$ by the fermentation of tryptophan ${ }^{(57)}$, an amino acid abundant in dairy products, red meat, eggs, fish and poultry. Overproduction of indole can lead to increased production of indoxyl sulphate, a uraemic toxin associated with chronic kidney disease ${ }^{(58)}$. Indole production is likely to have decreased in the RDA group due to the decreased quantity of tryptophan-rich foods in their diet. Indole did not increase in the $2 \mathrm{RDA}$ group possibly due to the preferential fermentation of fibre by gut microbiota, as indole production in particular is inhibited in the presence of fermentable carbohydrate ${ }^{(59)}$. The BCFA 2-methylbutyrate, 3-methylbutyrate and (a)

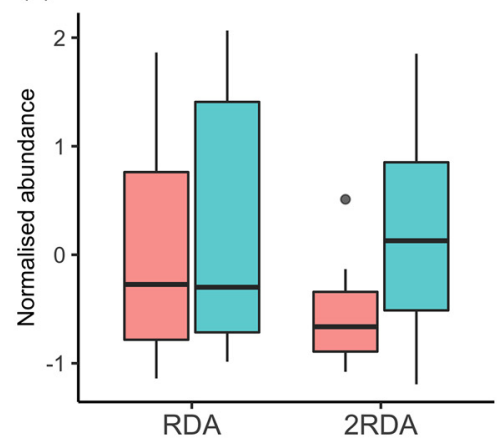

(d)

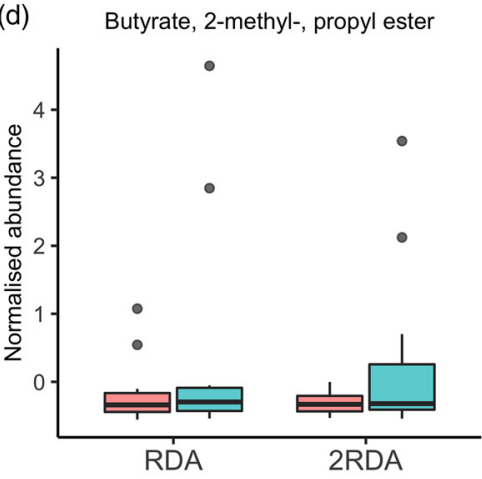

(b)

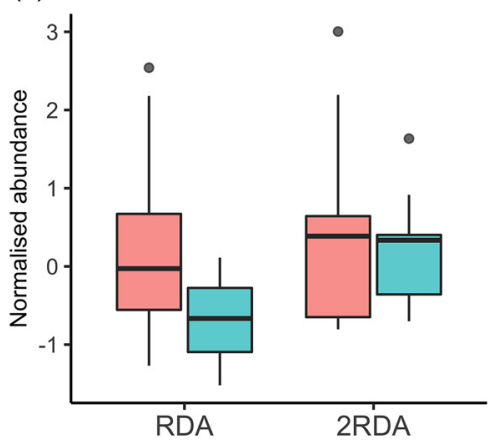

(e)

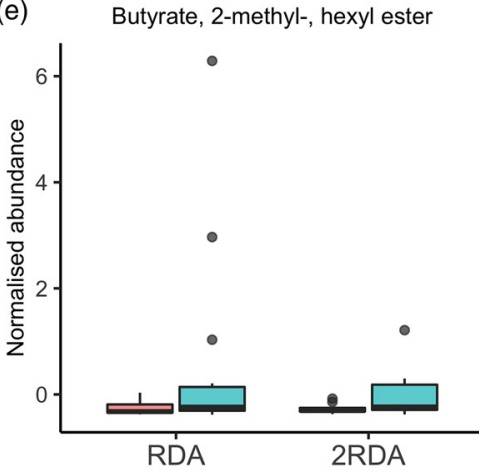

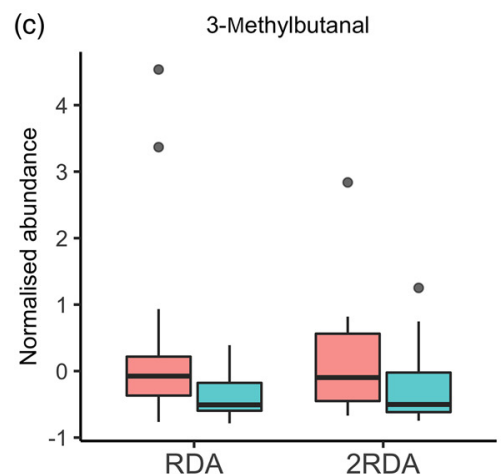

(f)

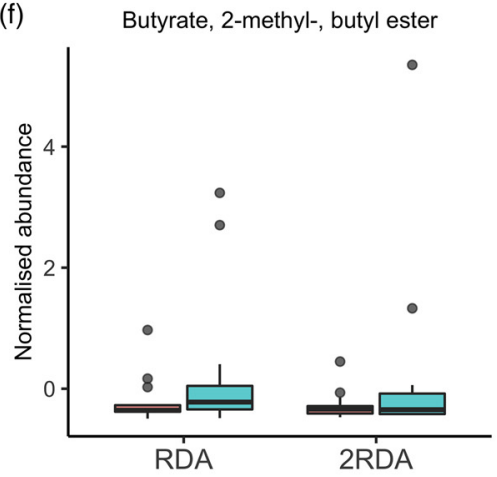

Time 追 Pre 追 Post

Fig. 7. Volatile organic compound boxplots. RDA, diet containing the RDA of protein; 2RDA, diet containing twice the RDA of protein. For the box plots: middle line is the median, boxes represent 25 th and 75 th percentiles, whiskers are within 1.5 interquartile ranges of the lower and upper percentiles, and dots represent outliers. 
isobutyrate are exclusively derived from microbial fermentation of the branched-chain amino acids (isoleucine, leucine and valine) ${ }^{(60)}$. For this reason BCFA abundance is often used as a biomarker for protein fermentation in the gut ${ }^{(53)}$, and increased BCFA abundance has been observed after high protein intake ${ }^{(17,52)}$. However, we did not observe an elevated abundance of BCFA in the 2RDA group relative to the $\mathrm{RDA}$ group, although some intermediary products of branched-chain amino acid catabolism were changed in both groups. 3-Methylbutanal (an oxygenated aldehyde) decreased in both groups over time. 3-Methylbutanal is an intermediate product of leucine degradation from Bacteroides taxa in the production of the BCFA 3-methylbutyrate ${ }^{(61)}$. In contrast, the carboxylic ester derivatives of the BCFA 2-methylbutyrate tended to increase in both groups over time. However, these esters are also common flavouring additives in foods ${ }^{(62)}$ and therefore it is uncertain if their abundance is reflective of microbial fermentative activity or dietary intake.

The main SCFA (butyrate, acetate and propionate), indicative measures of dietary fibre intake, were not altered despite the increased fibre intake in both study arms. As there are no other studies that have increased protein and fibre intake concurrently, comparison with previous research is challenging. Previous high-protein diet studies have demonstrated that SCFA, particularly butyrate, tend to decrease after a highprotein diet ${ }^{(17,18,63)}$, but these diets were accompanied by low fibre intake. Even a high-protein diet, without alteration in dietary fibre, decreased faecal butyrate concentrations ${ }^{(52)}$. The present findings are interesting, as it is well documented that increasing dietary fibre results in increased butyrate production in particular ${ }^{(64)}$, although a previous study with rats demonstrated that there is no linear correlation between fibre intake and SCFA production ${ }^{(65)}$. Regardless, due to the main site of production - the proximal colon - detection in faecal samples may not be wholly indicative of SCFA abundance. Additionally, SCFA are readily utilised by enterocytes or taken up via systemic circulation. The detection of increased SCFA in faecal samples is typically due to excessive production $^{(66)}$; however, it is conceivable that metabolism of SCFA in the elderly is altered, possibly due to changes in SCFA-producing bacteria and decreased microbial diversity ${ }^{(29)}$. As we did not include a younger cohort in this study by way of comparison, it is unclear if that is the case.

There was a high degree of inter-individual variation of gut microbiota composition, which persisted through the dietary intervention for both groups and was the predominant source of variation in the data. The degree of inter-individual variation could have been controlled by at least two approaches. First, using a cross-over study design reduces the variation at baseline as each participant serves as their own control. Although, as noted, a previous study employing a cross-over design presented similar findings to ours ${ }^{(52)}$. Second, subtle changes may have gone undetected in the small sample size. Indeed, a retrospective power calculation indicated that in order to detect at least a $30 \%$ effect, a total of ninety participants was required (forty-five per group). Elderly people are a heterogeneous population with large variability in physiological health, medication usage and lifestyle. This work investigated a small healthy cohort, which may not account for variations in gut microbial composition and metabolism in elderly accompanying co-morbidities or sex differences, or the frail and institutionalised.

Impaired capacity for nutrient absorption in the gastrointestinal tract may occur in the elderly; however, the literature is conflicting on whether digestion and absorption of protein are affected in healthy older adults ${ }^{(67)}$. As reported previously from this study, whole-body lean mass in the 2RDA group increased relative to the RDA group ${ }^{(35)}$, suggesting in part that greater absorption accompanies increased intake. Indeed, the primary protein sources that were increased in the 2RDA diet were dairy and animal proteins which are highly digestible ${ }^{(68)}$. Regardless, there will be malabsorption of protein and this will be approximately proportional to the amount of protein consumed ${ }^{(69,70)}$. Therefore, it can be reasonably expected that the metabolites from protein fermentation should be higher in the 2RDA group relative to the RDA group, and present in the faeces. In this study we did not detect evidence for this in the faeces using the HS/SPME/ GCMS method, therefore future studies may warrant closer examination of the bacterial $\mathrm{N}$ utilisation and/or corresponding measurement of absorbed bacterial metabolites and co-metabolites in the urine and/or plasma ${ }^{(71)}$. Indeed, as reported in a separate paper, we also observed increased concentrations of circulatory trimethylamine $N$-oxide (TMAO) in the 2RDA group ${ }^{(72)}$. TMAO is a co-metabolite, generated in the liver after gut microbial metabolism of choline and L-carnitine, nutrients that tend to be highest in protein-rich foods.

\section{Conclusion}

The present results suggest that consuming a diet with twice the RDA of protein for 10 weeks does not result in significant differences in proteolytic microbiota or metabolites of protein fermentation relative to the RDA of protein while achieving the recommended daily intake for fruits and vegetables. There was considerable inter-individual variation in both microbiota composition and VOC, which persisted through the intervention. Moreover, the artificial way by how every meal was provided is not indicative of real-world situations, although provision of protein and fibre through whole foods remains a unique strength. This study was not powered to detect subtle changes, therefore investigation of the interaction of protein intake on the gut microbiota is required within a larger cohort, and inclusive of the variations in dietary quality evident in a free-living elderly population. Such studies will be necessary to comprehensively appraise how dietary protein has an impact on microbial composition and function in the elderly.

\section{Acknowledgements}

We thank Matt Barnett for Strategic Science Investment Fund (SSIF) contract and reporting, Petra Hinterleitner, Elisabet Boman, Evelina Malmquist, Elina Holmstrand, Linnea Lind, Faith Chege, Fernando Tom and Elise Penning for their 
help with diet preparation and data collection, and Nicola Dryden for assistance with $16 \mathrm{~S}$ rDNA sequencing protocol.

The present study was supported by the New Zealand Ministry of Business, Innovation and Employment International Relationships and the European Union (IRSES-318962-BIOAGE), AgResearch Limited through the Strategic Science Investment Fund (contracts A19079 and A21246: Nutritional strategies for an ageing population).

The authors' responsibilities were as follows: Conceptualisation: D. C.-S. and C. J. M.; Methodology: D. C.-S., C. J. M. and A. M. M.; Formal analysis: S. M. M., A. M. M. and E. J. M.; Investigation: C. J. M., A. M. M., S. M. M., R. F. D., N. Z., F. R. and P. S.; Data curation: C. J. M., A. M. M., S. M. M. and N. A. G.; Writing - original draft preparation: S. M. M.; Writing - review and editing: E. J. M., A. M. M., C. J. M., R. F. D., N. Z, F. R., P. S., S. O. K., N. C. R., A. S., K.-H. W., J. O. S. and D. C.-S.; Supervision: D. C.-S., J. O. S., C. J. M. and A. M. M.; Funding acquisition: D. C.-S., N. C. R. and S. O. K.; all authors approved the final version of the manuscript for submission.

There are no conflicts of interest.

\section{Supplementary material}

The supplementary material for this article can be found at https://doi.org/10.1017/jns.2020.15

\section{References}

1. Beard JR, Officer AM \& Cassels AK (2016) The world report on ageing and health. Gerontologist 56, Suppl. 2, S163-S1S6.

2. World Health Organization (2007) Protein and Amino Acid Requirements in Human Nutrition. World Health Organization Technical Report Series no. 935. Geneva: WHO.

3. United States Department of Agriculture (2015) 2015-2020 Dietary Guidelines for Americans, 8th ed. Washington, DC: USDA.

4. Bauer J, Biolo G, Cederholm T, et al. (2013) Evidence-based recommendations for optimal dietary protein intake in older people: a position paper from the PROT-AGE study group. J Am Med Dir Assoc 14, 542-559.

5. Houston DK, Nicklas BJ, Ding J, et al. (2008) Dietary protein intake is associated with lean mass change in older, community-dwelling adults: the Health, Aging, and Body Composition (Health ABC) study. Am J Clin Nutr 87, 150-155.

6. Gorissen SHM, Trommelen J, Kouw IWK, et al. (2020) Protein type, protein dose, and age modulate dietary protein digestion and phenylalanine absorption kinetics and plasma phenylalanine availability in humans. J Nutr, nxaa024 (epublication ahead of print version 18 February 2020).

7. Windey K, De Preter V \& Verbeke K (2012) Relevance of protein fermentation to gut health. Mol Nutr Food Res 56, 184-196.

8. Juraschek SP, Appel LJ, Anderson CAM, et al. (2013) Effect of a high-protein diet on kidney function in healthy adults: results from the Omni Heart trial. Am J Kidney Dis 61, 547-554.

9. Jantchou P, Morois S, Clavel-Chapelon F, et al. (2010) Animal protein intake and risk of inflammatory bowel disease: the E3N prospective study. Am J Gastroenterol 105, 2195-2201.

10. Jowett S, Seal C, Pearce M, et al. (2004) Influence of dietary factors on the clinical course of ulcerative colitis: a prospective cohort study. Gut 53, 1479-1484.

11. Norat T \& Riboli E (2001) Meat consumption and colorectal cancer: a review of epidemiologic evidence. Nutr Rev 59, 37-47.
12. Wu GD, Bushmanc FD \& Lewis JD (2013) Diet, the human gut microbiota, and IBD. Anaerobe 24, 117-120.

13. Clemente Jose C, Ursell Luke K, Parfrey Laura W, et al. (2012) The impact of the gut microbiota on human health: an integrative view. Cell 148, 1258-1270.

14. Conlon M \& Bird A (2015) The impact of diet and lifestyle on gut microbiota and human health. Nutrients 7, 17-44.

15. Moschen AR, Wieser V \& Tilg H (2012) Dietary factors: major regulators of the gut's microbiota. Gut Liver 6, 411-416.

16. Xu Z \& Knight R (2014) Dietary effects on human gut microbiome diversity. Br J Nutr 113, S1-S5.

17. Russell WR, Gratz SW, Duncan SH, et al. (2011) High-protein, reduced-carbohydrate weight-loss diets promote metabolite profiles likely to be detrimental to colonic health. Am J Clin Nutr 93, 10621072.

18. Duncan SH, Belenguer A, Holtrop G, et al. (2007) Reduced dietary intake of carbohydrates by obese subjects results in decreased concentrations of butyrate and butyrate-producing bacteria in feces. Appl Environ Microbiol 73, 1073-1078.

19. David LA, Maurice CF, Carmody RN, et al. (2014) Diet rapidly and reproducibly alters the human gut microbiome. Nature 505, 559-563.

20. Koh A, De Vadder F, Kovatcheva-Datchary P, et al. (2016) From dietary fiber to host physiology: short-chain fatty acids as key bacterial metabolites. Cell 165, 1332-1345.

21. Portune KJ, Beaumont M, Davila A-M, et al. (2016) Gut microbiota role in dietary protein metabolism and health-related outcomes: the two sides of the coin. Trends Food Sci Technol 57, 213-232.

22. Yao CK, Muir JG \& Gibson PR (2016) Review article: insights into colonic protein fermentation, its modulation and potential health implications. Aliment Pharmacol Ther 43, 181-196.

23. Walker AW, Ince J, Duncan SH, et al. (2011) Dominant and diet-responsive groups of bacteria within the human colonic microbiota. ISME J 5, 220-230.

24. Ross AB, Pere-Trépat E, Montoliu I, et al. (2013) A whole-grain-rich diet reduces urinary excretion of markers of protein catabolism and gut microbiota metabolism in healthy men after one week. J Nutr 143, 766-773.

25. Birkett A, Muir J, Phillips J, et al. (1996) Resistant starch lowers fecal concentrations of ammonia and phenols in humans. $A m \mathrm{~J}$ Clin Nutr 63, 766-772.

26. Winter J, Nyskohus L, Young GP, et al. (2011) Inhibition by resistant starch of red meat-induced promutagenic adducts in mouse colon. Cancer Prev Res 4, 1920-1928.

27. De Filippis F, Pellegrini N, Vannini L, et al. (2016) High-level adherence to a Mediterranean diet beneficially impacts the gut microbiota and associated metabolome. Gut 65, 1812-1821.

28. An R, Wilms E, Masclee AA, et al. (2018) Age-dependent changes in GI physiology and microbiota: time to reconsider? Gut 67, 22132222.

29. Salazar N, Arboleya S, Valdes L, et al. (2014) The human intestinal microbiome at extreme ages of life. Dietary intervention as a way to counteract alterations. Front Genet 5, 406.

30. Salazar N, Valdés-Varela L, González S, et al. (2017) Nutrition and the gut microbiome in the elderly. Gut Microbes 8, 82-97.

31. Rampelli S, Candela M, Turroni S, et al. (2013) Functional metagenomic profiling of intestinal microbiome in extreme ageing. Aging (Albany NY) 5, 902-912.

32. Woodmansey EJ, McMurdo MET, Macfarlane GT, et al. (2004) Comparison of compositions and metabolic activities of fecal microbiotas in young adults and in antibiotic-treated and non-antibiotic-treated elderly subjects. Appl Environ Microbiol 70, 6113

33. Volpi E, Campbell WW, Dwyer JT, et al. (2012) Is the optimal level of protein intake for older adults greater than the recommended dietary allowance? J Gerontol Series A 68, 677-681.

34. Haahr M \& Haahr S (1998) Random integer generator. http:// www.random.org/integers/ (accessed April 2010).

35. Mitchell CJ, Milan AM, Mitchell SM, et al. (2017) The effects of dietary protein intake on appendicular lean mass and muscle 
function in elderly men: a 10 -wk randomized controlled trial. Am J Clin Nutr 106, 1375-1383.

36. New Zealand Ministry of Health (2013) Food and Nutrition Guidelines for Healthy Older People: A Background Paper. Wellington: Ministry of Health.

37. Gerrior S, Juan W \& Peter B (2006) An easy approach to calculating estimated energy requirements. Prev Chronic Dis 3, A129.

38. Karu N, Deng L, Slae M, et al. (2018) A review on human fecal metabolomics: methods, applications and the human fecal metabolome database. Anal Chim Acta 1030, 1-24.

39. Cardona S, Eck A, Cassellas M, et al. (2012) Storage conditions of intestinal microbiota matter in metagenomic analysis. BMC Microbiol 12, 158.

40. Ahmed I, Smith S \& Probert C (editors) (2009) Volatile organic compounds as diagnostic faecal biomarkers in inflammatory bowel disease method development. Gut 58, Suppl. 1, A63.

41. Giannoukos G, Ciulla DM, Huang K, et al. (2012) Efficient and robust RNA-seq process for cultured bacteria and complex community transcriptomes. Genome Biol 13, R23.

42. ThermoFisher Scientific (2016) Ion Reporter: Metagenomics 16S Algorithms Overview. http://tools.thermofisher.com/content/ sfs/brochures/ion-reporter-16s-metagenomics-algorithms-whitepaper.pdf (accessed June 2020).

43. Stein SE (1999) An integrated method for spectrum extraction and compound identification from gas chromatography/mass spectrometry data. J Am Soc Mass Spectrom 10, 770-781.

44. Stein SE (2014) NIST Mass Spectral Library. Gaithersburg, MD: National Institute of Science and Technology.

45. Sumner LW, Amberg A, Barrett D, et al. (2007) Proposed minimum reporting standards for chemical analysis. Metabolomics 3, 211-221.

46. Smith CA, Want EJ, O'Maille G, et al. (2006) XCMS: processing mass spectrometry data for metabolite profiling using nonlinear peak alignment, matching, and identification. Anal Chem 78, 779-787.

47. Salonen A, Lahti L, Salojärvi J, et al. (2014) Impact of diet and individual variation on intestinal microbiota composition and fermentation products in obese men. ISME J 8, 2218-2230.

48. Dhariwal A, Chong J, Habib S, et al. (2017) Microbiomeanalyst: a web-based tool for comprehensive statistical, visual and meta-analysis of microbiome data. Nucleic Acids Res 45, W180-W188.

49. Chong J, Soufan O, Li C, et al. (2018) Metaboanalyst 4.0: towards more transparent and integrative metabolomics analysis. Nucleic Acids Res 46, W486-W494.

50. Morgan XC, Tickle TL, Sokol H, et al. (2012) Dysfunction of the intestinal microbiome in inflammatory bowel disease and treatment. Genome Biol 13, R79.

51. Singh RK, Chang H-W, Yan D, et al. (2017) Influence of diet on the gut microbiome and implications for human health. J Transl Med 15, 73.

52. Beaumont M, Portune KJ, Steuer N, et al. (2017) Quantity and source of dietary protein influence metabolite production by gut microbiota and rectal mucosa gene expression: a randomized, parallel, double-blind trial in overweight humans. Am J Clin Nutr 106, 1005-1019.

53. Windey K, De Preter V, Louat T, et al. (2012) Modulation of protein fermentation does not affect fecal water toxicity: a randomized cross-over study in healthy subjects. PLOS ONE 7, e52387.

54. Wu GD, Chen J, Hoffmann C, et al. (2011) Linking long-term dietary patterns with gut microbial enterotypes. Science 334, 105-108.
55. Apajalahti J (2005) Comparative gut microflora, metabolic challenges, and potential opportunities. J Appl Poult Res 14, 444-453.

56. Devlin AS, Marcobal A, Dodd D, et al. (2016) Modulation of a circulating uremic solute via rational genetic manipulation of the gut microbiota. Cell Host Microbe 20, 709-715.

57. Smith EA \& Macfarlane GT (1997) Dissimilatory amino acid metabolism in human colonic bacteria. Anaerobe 3, 327-337.

58. Meijers BK \& Evenepoel P (2011) The gut-kidney axis: indoxyl sulfate, P-cresyl sulfate and CKD progression. Nephrol Dial Transplant 26, 759-761.

59. Smith EA \& Macfarlane GT (1996) Enumeration of human colonic bacteria producing phenolic and indolic compounds: effects of $\mathrm{pH}$, carbohydrate availability and retention time on dissimilatory aromatic amino acid metabolism. J Appl Bacteriol 81, 288-302.

60. Macfarlane GT\& Cummings JH (1991) The colonic flora, fermentation and large bowel digestive function. In The Large Intestine: Physiology, Pathophysiology and Disease, pp. 51-92 [SF Phillips, JH Pemberton and RG Shorter, editors]. New York: Raven Press.

61. Díaz-Pérez AL, Díaz-Pérez C \& Campos-García J (2016) Bacterial L-leucine catabolism as a source of secondary metabolites. Rev Environ Sci Bio/Technol 15, 1-29.

62. Wishart DS, Tzur D, Knox C, et al. (2007) HMDB: the human metabolome database. Nucleic Acids Res 35, D521-D526.

63. Brinkworth GD, Noakes M, Clifton PM, et al. (2009) Comparative effects of very low-carbohydrate, high-fat and high-carbohydrate, low-fat weight-loss diets on bowel habit and faecal short-chain fatty acids and bacterial populations. Br J Nutr 101, 1493-1502.

64. So D, Whelan K, Rossi M, et al. (2018) Dietary fiber intervention on gut microbiota composition in healthy adults: a systematic review and meta-analysis. Am J Clin Nutr 107, 965-983.

65. Levrat M-A, Rémésy C \& Demigné C (1991) High propionic acid fermentations and mineral accumulation in the cecum of rats adapted to different levels of inulin. J Nutr 121, 1730-1737.

66. De Filippo C, Cavalieri D, Di Paola M, et al. (2010) Impact of diet in shaping gut microbiota revealed by a comparative study in children from Europe and rural Africa. Proc Natl Acad Sci US A 107, 14691-14696.

67. Harper EJ (1998) Changing perspectives on aging and energy requirements: aging and digestive function in humans, dogs and cats. J Nutr 128, 2632S-2635S.

68. Gilbert J-A, Bendsen NT, Tremblay A, et al. (2011) Effect of proteins from different sources on body composition. Nitr Metab Cardiovasc Dis 21, B16-B31.

69. Cummings J \& Macfarlane G (1991) The control and consequences of bacterial fermentation in the human colon. J Appl Bacteriol 70, 443-459.

70. Silvester KR \& Cummings JH (1995) Does digestibility of meat protein help explain large bowel cancer risk? Nutr Cancer 24, 279-288.

71. Jain A, Li XH \& Chen WN (2019) An untargeted fecal and urine metabolomics analysis of the interplay between the gut microbiome, diet and human metabolism in Indian and Chinese adults. Sci Rep 9, 9191.

72. Mitchell SM, Milan AM, Mitchell CJ, et al. (2019) Protein intake at twice the RDA in older men increases circulatory concentrations of the microbiome metabolite trimethylamine- $N$-oxide (TMAO). Nutrients 11, 2207. 